\title{
MITIGAÇÃO DA VOLUNTARIEDADE: UMA ANÁLISE DA VEDAÇÃO DE INTIMAÇÃO JUDICIAL PARA PRÁTICAS RESTAURATIVAS ${ }^{1}$
}

\section{MITIGATION OF VOLUNTEERING: AN ANALYSIS OF THE JUDICIAL SUBPOENA SEAL FOR RESTORATIVE PRACTICES}

Sandoval Alves da Silva Doutor e mestre em Direito pela UFPA. Procurador do trabalho lotado na Procuradoria Regional do Trabalho da $8 .^{\mathrm{a}}$ Região. Professor da UFPA na Pós-Graduação e na Graduação de Direito. Líder do Grupo de Pesquisa "Comunidade, conflitos, problemas, insatisfações sociais e o estudo sobre paz” (CNPq). Belém/PA. https://orcid.org/0000-0002-17952281. http://lattes.cnpq.br/2744878887909140. E-mail: sandovalsilva4@yahoo.com.br.

Camille de Azevedo Alves Graduanda em Direito pela UFPA. Bolsista de Extensão no Projeto "A aplicação das práticas restaurativas no Núcleo de Prática Jurídica da Universidade Federal do Pará como um processo acadêmico da extensão universitária" (2019-2020). Voluntária no Projeto de Extensão Capacitação de acesso à justiça no Projeto Escrevendo e Reescrevendo a Nossa História (PERNOH) (2019-atual). Bolsista PIBIC/UFPA (2017-2018). Membro do Grupo de Pesquisa "Tradição da Lei Natural" (CNPq) e do Grupo de Pesquisa "Comunidade, conflitos, problemas, insatisfações sociais e o estudo sobre paz" (CNPq). Belém/PA. https://orcid.org/0000-0002-2879088X. http://lattes.cnpq.br/3381321326552718. E-mail: camilledeazevedoalves@gmail.com.

\footnotetext{
${ }^{1}$ Artigo recebido em 06/10/2020 e aprovado em 15/12/2020.
} 
João Renato Rodrigues Siqueira Graduando em Direito pela UFPA; bolsista de iniciação científica PIBIC 2019-2020; voluntário PIBEX 2019-atual; Membro do grupo de Pesquisa "Tradição da Lei Natural" (CNPq) e do Grupo de Pesquisa "Comunidade, conflitos, problemas, insatisfações sociais e o estudo sobre paz" (CNPq). Belém/PA. $\quad$ https://orcid.org/0000-0002-5411-7322. http://lattes.cnpq.br/0696701101651511. E-mail: joao.renato.rs@gmail.com.

RESUMO: Aborda-se a vedação da intimação dos envolvidos a participarem de práticas restaurativas, visando analisar a possibilidade de mitigação do princípio da voluntariedade da Justiça Restaurativa, à luz da teoria da jurisdição por substituição. No Judiciário os sujeitos renunciam a vontade individual ou coletiva original, de maneira que o juiz pode intimá-los a participarem de determinados atos judiciais. Conclui-se que, a intimação embora contrarie a vontade individual ou coletiva de participar, está em consonância com a vontade de ser substituído, expressa no ato da demanda, e a vontade geral expressa no ordenamento jurídico de substituir os envolvidos nas demandas.

PALAVRAS-CHAVE: Poder Judiciário; Substituição judicial; Intimação; Justiça Restaurativa; Voluntariedade.

ABSTRACT: This study approach the sealing of the judicial subpoena of those involved to participate in restorative practices, to analyze the possibility of mitigating the principle of willingness of the Restorative Justice, in the light of the substitution jurisdiction theory. In the Judiciary the subjects are replaced, that is, they renounce their original individual or collective will, so that the judge can instruct them to participate in certain judicial acts. It is concluded that the subpoena, although it contradicts the individual or collective will to participate, is in line with the will to be replaced, expressed in the act of demand, and the general will expressed in the legal order to replace those involved in the demands. 
KEYWORDS: Judiciary; Judicial replacement; Subpoena; Restorative Justice. Willingness.

\section{INTRODUÇÃO}

O artigo 334 do Código de Processo Civil (CPC) de 2015 obriga a realização de audiências de conciliação e de mediação quando a petição inicial preencher os requisitos essenciais e não for o caso de improcedência liminar do pedido².

Assim, ao receber a demanda, o juiz intima os envolvidos a participarem de um procedimento que objetiva estimular o seu protagonismo e em que eles poderão decidir autocompositiva e originariamente acerca dos conflitos, dos problemas e das insatisfações sociais (CPIS) sozinhos.

Assim, no ato da demanda, um dos sujeitos pede para que o juiz o substitua na solução daquele CPIS, "incapacitando-se" e substituindo-se relacional decisoriamente. Todavia, pelo CPC, o juiz, ao receber os autos do processo, devolve-os procedimentalmente aos envolvidos para que possa haver alguma autocomposição primariamente. Por outras palavras, para que os sujeitos envolvidos no conflito possam tentar, por suas próprias razões relacionais, solucionar, administrar ou transformar seus CPIS de forma a estimular o protagonismo, antes do procedimento de substituição relacional decisória e da apreciação do mérito por um terceiro. Portanto, observa-se que, na conciliação e na mediação realizadas no Judiciário, os sujeitos envolvidos no litígio, a priori, não são substituídos, embora, no exercício do direito de ação processual, já tenham formulado o pedido para sê-lo.

Ademais, o direito ao procedimento adequado deve ser interpretado de forma a possibilitar que seja aplicado o procedimento mais adequado ao caso concreto, ao objeto material e às necessidades dos sujeitos envolvidos.

Desse modo, se o procedimento mais adequado for o restaurativo, ele poderá ser aplicado, tal qual a conciliação e a mediação, visto que a audiência deve ser entendida como hábil para todas as formas autocompositivas e não limitada a duas técnicas de autocomposição, de maneira que o direito ao procedimento pode revelar a técnica de resolução que poderia ser mais bem aplicada, ainda que em forma de tentativas e erros.

\footnotetext{
${ }^{2}$ BRASIL. Lei n. ${ }^{\circ}$ 13.105, de 16 de março de 2015. Código de Processo Civil. Diário Oficial da União, Brasília, DF, 17 mar. 2015.
} 
Assim, quando o procedimento restaurativo for o procedimento mais indicado ao caso, devese tentar, primeiro, tal procedimento.

Logo, em uma interpretação ampliativa, pode-se compreender que o artigo 334 do CPC/2015, que obriga a realização de audiências de conciliação e de mediação, obriga o juiz, no momento inicial do processo, a permitir as diversas formas de autocomposição, pois o procedimento serve para buscar o protagonismo originário dos envolvidos, evitando-se a técnica processual derivada de vontades no regime de substituição dos envolvidos pelo juiz, sem que isso represente negativa de tutela jurisdicional ou violação do acesso à justiça.

Contudo, embora o juiz possa intimar os sujeitos processuais a participarem de audiências de conciliação e de mediação, o artigo 8. ${ }^{\circ}$ da Resolução n. ${ }^{\circ}$ 225/2016 do Conselho Nacional de Justiça $(\mathrm{CNJ})^{3}$ veda a intimação judicial para as sessões de procedimentos restaurativos. Tal vedação baseia-se no princípio da voluntariedade, que busca a atuação dos envolvidos sem que exista, prima facie, qualquer forma de coação, de constrangimento ou de obrigatoriedade.

Dessa forma, ao sugerir-se a aplicação da Justiça Restaurativa, deve ser esclarecido aos participantes o que é a Justiça Restaurativa, sua forma de execução e suas consequências. Além disso, deve-se explicar as consequências do processo judicial para que os sujeitos envolvidos possam compreender e decidir com segurança se querem participar ou não, assinando, em caso positivo, um termo de consentimento.

Todavia, o princípio da voluntariedade, concebido na Justiça Restaurativa como voluntariedade individual de cada participante ao consentir participar do procedimento restaurativo, pode, em determinadas situações, colidir com a voluntariedade geral. Com efeito, a lei, enquanto reflexo da vontade geral, determina que o Judiciário substitua os envolvidos na resolução de seus CPIS, decidindo por eles com base no ordenamento jurídico (incapacitação relacional decisória).

Logo, questiona-se: em que medida a vedação da intimação judicial para as sessões de procedimentos restaurativos, prevista no artigo $8 .^{\circ}$ da Resolução n. ${ }^{\circ}$ 225/2016 do CNJ, atenta contra o princípio da voluntariedade? Quando o procedimento de substituição processual foi acionado, devemos seguir a voluntariedade originária ou a derivada? Ou, por

\footnotetext{
${ }^{3}$ BRASIL. Conselho Nacional de Justiça. Resolução n. ${ }^{2} 225$, de 31 de maio de 2016. Dispõe sobre a Política Nacional de Justiça Restaurativa no âmbito do Poder Judiciário e dá outras providências. DJe/CNJ, n. 91, p. 28-33, 2 jun. 2016.
} 
outro lado, em que medida o princípio da voluntariedade, concebido de forma originária pela Justiça Restaurativa e assim materializado na resolução, precisa ser mitigado no contexto da jurisdição por substituição?

A hipótese do trabalho é de que no Judiciário os envolvidos são substituídos, isto é, abrem mão de sua vontade individual originária, de forma que o juiz pode intimá-los a praticarem determinados atos judiciais e a deles participarem; o juiz pode, principalmente, decidir por eles o caso, assumindo obrigações pelos sujeitos envolvidos nos CPIS, salvo se ficar claro que tais sujeitos voluntariamente rejeitam a resolução, a administração ou a transformação pelo exercício de suas próprias razões relacionais.

Nesse caso, o procedimento de substituição judicial deve prosseguir, pois nada é mais incapacitante para os envolvidos do que ter um terceiro decidindo sobre atos e consequências dos traumas vivenciados por outras pessoas, em clara situação de ausência de vivência, que deve ser trazida aos autos pelos meios probatórios.

Logo, se o juiz pode, contra a vontade do substituído, impor-lhe o ônus de participar de um procedimento autoritário de decisão unilateral, em que a vontade originária dos envolvidos é substituída por um terceiro, o juiz pode intimá-lo a participar de um processo autocompositivo que estimule o seu protagonismo originário relacional na solução, na administração e na transformação de seus CPIS.

Embora essa afirmação contrarie a vontade originária de participar, está em consonância com (1) a vontade individual ou coletiva originária de ser substituído, expressa no ato da demanda, e com (2) a vontade geral expressa no ordenamento jurídico de (2.1) substituir os sujeitos envolvidos nas demandas, intimando-os, e de (2.2) incentivar a autocomposição, quando se trata do procedimento de tentativa de autocomposição, salvo se ambas as partes manifestarem, expressamente, desinteresse na composição consensual ou não se admitir a autocomposição, nos termos do $§ 4 .^{\circ}$ do artigo 334 do CPC/2015.

Utiliza-se aqui o método de abordagem hipotético-dedutivo: propõe-se uma hipótese para o problema e tenta-se averiguá-la ao longo do trabalho. Como método de procedimento, adota-se a pesquisa bibliográfica para a obtenção de dados e de argumentos a fim de confirmar ou desqualificar a hipótese levantada.

Na primeira seção, aborda-se a Justiça Restaurativa e um de seus princípios basilares, o da voluntariedade ou do consentimento. Na segunda seção, apresentam-se algumas 
resoluções acerca da Justiça Restaurativa, enfocando, entre suas inovações, a possibilidade de intimar os envolvidos a participarem de práticas restaurativas. Na terceira seção, examinase a possibilidade da mitigação do princípio da voluntariedade da Justiça Restaurativa à luz da teoria da jurisdição por substituição.

\section{A JUSTIÇA RESTAURATIVA E O PRINCÍPIO DA VOLUNTARIEDADE}

Fontes históricas e antropológicas apontam a existência de vestígios do que hoje é chamado "práticas restaurativas" em comunidades ${ }^{4}$ da África, da Nova Zelândia, da Austrália e das Américas. Todavia, algumas dessas práticas foram sufocadas pelas diversas dominações que esses povos sofreram e muitas sumiram devido à centralização do poder estatal dominante ${ }^{5}$.

A inspiração do modelo restaurativo atual remonta às tradições ancestrais dos Maoris, da Nova Zelândia, e das culturas indígenas do Canadá6. Na Nova Zelândia, a Justiça Restaurativa começou a ganhar os contornos que hoje conhecemos, destacando-se no âmbito do direito penal nas infrações infantojuvenis, como um modo de lidar com crimes de menor potencial ofensivo ou crimes patrimoniais ${ }^{7}$.

Nessas comunidades, inexistia a figura do juiz centralizador, detentor da Jurisdição, do poder coercitivo e responsável pela solução dos conflitos. A comunidade, conscientemente, quando se via diante de uma situação em que o convívio harmônico era abalado ou ameaçado por um ato contrário à cultura do grupo, aplicava a forma de reparação para restabelecer o equilíbrio afetado ${ }^{8}$.

\footnotetext{
${ }^{4}$ Em razão do corte metodológico, apesar de haver fortes diferenças conceituais entre "comunidade" e "sociedade", será aqui utilizado o primeiro termo para representar a comunidade ou a coletividade, por significar melhor a ideia defendida. Para aprofundar o tema, consultar TORRES CARRILLO, Alfonso. El retorno a la comunidad: problemas, debates y desafíos de vivir juntos. Bogotá: El Búho, 2013.

5 JACCOUD, Mylène. Princípios, tendências e procedimentos que cercam a justiça restaurativa. In: SLAKMON, Catherine; DE VITTO, Renato Campos Pinto; PINTO, Renato Sócrates Gomes (org.). Justiça restaurativa. Brasília, DF: Ministério da Justiça; Programa das Nações Unidas para o Desenvolvimento, 2005. p. 163-164.

${ }^{6}$ PINTO, Renato Sócrates Gomes. Justiça restaurativa é possível no Brasil? In: SLAKMON, Catherine; VITTO, Renato Campos Pinto de; PINTO, Renato Sócrates Gomes. Justiça restaurativa: coletânea de artigos. Brasília, Ministério da Justiça; Programa das Nações Unidas para o Desenvolvimento, 2005. p. 23.

${ }^{7}$ ZEHR, Howard. Justiça restaurativa: teoria e prática. Tradução de Tônia Van Acker. 2. ed. ampl. e atual. São Paulo: Palas Athena, 2015, p. 12.

${ }^{8}$ SILVA, Elizabet Leal da. Justiça restaurativa como meio alternativo de solução de conflito. Arquivo Jurídico, Teresina, v. 1, n. 6, jan./jun. 2014, p. 24.
} 
Assim sendo, constata-se que, nas comunidades em que os interesses coletivos superam os individuais (ou melhor, os interesses individuais decorrem do coletivo), a transgressão desencadeia reações orientadas para o restabelecimento do equilíbrio rompido, bem como as ações dirigem-se à busca de uma solução rápida para o problema. As formas punitivas não foram excluídas das comunidades, pois ainda havia a penalização do transgressor, mas o infrator e a comunidade sentiam-se corresponsáveis pelo ato ilícito 9 .

Portanto, a Justiça Restaurativa surgiu em comunidades em que não havia a figura do Estado-juiz, enquanto figura detentora do monopólio da função jurisdicional, de prestígio e da coerção institucionalizada e legalizada, tal como se apresentou ao longo do tempo. Dessa forma, pode-se afirmar que a Justiça Restaurativa provém da inadequação dos meios estatais para resolver determinadas demandas, buscando abordagens que propiciem a participação de todos por meio de decisões coletivas em que os envolvidos constroem respostas compartilhadas para lidar com as consequências de um ato que afetou toda a comunidade e com suas implicações para o futuro ${ }^{10}$.

Logo, a origem da Justiça Restaurativa remonta a uma forma colaborativa, cooperativa e comunitária de resolução, de administração e de transformação de conflitos, de problemas e de insatisfações sociais (CPIS) ${ }^{11}$ com a participação de toda a comunidade, isto é, de todos os afetados pelo conflito.

Sendo assim, a Justiça Restaurativa busca dar protagonismo aos envolvidos na resolução de seus próprios conflitos, buscando métodos participativos de deliberação e de solução, de administração ou de transformação de conflitos, de problemas e de insatisfações sociais (CPIS). Consequentemente, um dos pilares da Justiça Restaurativa é a voluntariedade.

9 JACCOUD, Mylène. Princípios, tendências e procedimentos que cercam a justiça restaurativa. In: SLAKMON, Catherine; DE VITTO, Renato Campos Pinto; PINTO, Renato Sócrates Gomes (org.). Justiça restaurativa. Brasília, DF: Ministério da Justiça; Programa das Nações Unidas para o Desenvolvimento, 2005. p. 164.

${ }^{10}$ MARSHALL, Tony F. Restorative Justice: An Overview. London: Home Office Research and Development Statistics Directorate, 1999.

${ }^{11}$ Compreende-se que nem todos os CPIS são solucionáveis, alguns conseguem ser apenas administráveis enquanto perduram e outros podem ser transformados, logo, podem-se estimular mudanças construtivas a partir do conflito. Ademais, neste artigo, as palavras "conflito" ou "problema" referem-se, necessariamente, aos CPIS. Essa perspectiva pode ser aprofundada no artigo SILVA, Sandoval Alves da; SIQUEIRA, João Renato Rodrigues. Acesso à justiça no Projeto "Escrevendo e Reescrevendo a Nossa História" (Pernoh). Revista InterAção, [s.l.], v. 10, n. 2, p. 41-51, jun./dez. 2019. 
Revista Eletrônica de Direito Processual - REDP.

Rio de Janeiro. Ano 15. Volume 22. Número 2. Maio a Agosto de 2021

Periódico Quadrimestral da Pós-Graduação Stricto Sensu em Direito Processual da UERJ

Patrono: José Carlos Barbosa Moreira (in mem.). ISSN 1982-7636. pp. 648-669

www.redp.uerj.br

Segundo Marshall, Boyack e Bowen ${ }^{12}$, um procedimento para ser considerado restaurativo requer a participação voluntária dos envolvidos nos procedimentos e técnicas restaurativas. Ninguém deve ser coagido a participar, tampouco a continuar no processo e/ou ser compelido a se comunicar contra a sua vontade. Consequentemente, o procedimento não é restaurativo se os participantes estão presentes sob coação ou se for esperado que falem, ajam ou decidam sobre o que está sendo discutido de maneira contrária a seus desejos e a suas necessidades.

Nesse contexto, compreende-se que a coerção inviabilizaria o sucesso das práticas restaurativas, que necessitam de engajamento e de sincera abertura dos envolvidos, para alcançar o resultado restaurativo ${ }^{13}$.

Oliveira ${ }^{14}$, ao falar especificamente sobre a prática circular, esclarece que, ainda na fase do pré-círculo, os envolvidos devem assinar um termo de consentimento, a fim de assegurar aos participantes a plena clareza das informações sobre o encontro, para que decidam voluntariamente se querem ou não ingressar na ambiência restaurativa.

Ainda segundo Oliveira ${ }^{15}$, a prática restaurativa pode ser aplicada mesmo que algum dos participantes não a queira. Nesse caso, será aplicada apenas com os que consentiram, enfatizando-se as necessidades dos receptores secundários (familiares e comunidade), ou fazendo-se a representação dos protagonistas do encontro (vítima e ofensor) por um familiar ou amigo, ou ainda se conseguindo que a parte ausente se manifeste por escrito ou por meio audiovisual.

Tal compreensão advém da diferença entre consentimento individual e geral ${ }^{16}$. O princípio da voluntariedade, concebido na Justiça Restaurativa como consentimento

\footnotetext{
${ }^{12}$ MARSHALL, Chris; BOYACK, Jim; BOWEN, Helen. Como a Justiça Restaurativa assegura a boa prática: uma abordagem baseada em valores. In: SLAKMON, Catherine; DE VITTO, Renato Campos Pinto; PINTO, Renato Sócrates Gomes (org.). Justiça Restaurativa: coletânea de artigos. Brasília, DF: Ministério da Justiça; Programa das Nações Unidas para o Desenvolvimento, 2005. p. 274.

${ }^{13}$ SILVA, Karina Duarte Rocha da. Justiça Restaurativa e sua aplicação no Brasil. 2007. 83 f. Monografia (Bacharelado em Direito) - Faculdade de Direito, Universidade de Brasília, Brasília, DF, 2007, p. 38.

${ }^{14}$ OLIVEIRA, Frederico dos Santos. Círculo restaurativo e procedimento judicial: análise de uma axiologia (as)simétrica. Caruaru: Asces, 2019, p. 131-132.

15 OLIVEIRA, Frederico dos Santos. Círculo restaurativo e procedimento judicial: análise de uma axiologia (as)simétrica. Caruaru: Asces, 2019, p. 132.

${ }^{16}$ Salienta-se que existe um debate acerca da representatividade do Poder Legislativo e discute-se se as leis promulgadas seriam ou não uma representação da vontade geral do povo, como pode ser visto em MENDES, Conrado Hübner. Direitos fundamentais, separação de poderes e deliberação. São Paulo: Saraiva, 2011, que se apoia em autores como Jeremy Waldron, Lon Fuller, Wilfrid Waluchow, entre outros. De igual modo, salienta-se que se conhece o debate acerca do papel da "vontade geral" e da carga semântica diferente que essa expressão carrega nas teorias desenvolvidas por autores como, por exemplo, ROUSSEAU, Jean-Jacques.
} 
individual de cada participante ao engajar-se no procedimento restaurativo, pode, em certas situações, colidir com a voluntariedade geral. De fato, a lei, enquanto reflexo da vontade geral, determina que o Judiciário substitua os envolvidos na resolução de seus CPIS, decidindo por eles com base no ordenamento jurídico (incapacitação relacional decisória), como será mais bem explicado nas seções seguintes.

Diante desse panorama da Justiça Restaurativa, em que se destaca o papel da voluntariedade individual e geral, passemos à análise dos marcos normativos que culminaram na vedação de intimação para práticas restaurativas.

\section{A VEDAÇÃO DE INTIMAÇÃO PARA PRÁTICAS RESTAURATIVAS}

Umas das primeiras resoluções que abordam a Justiça Restaurativa, ainda em âmbito internacional, é a Resolução n. ${ }^{\circ}$ 12, de 2002, da Organização das Nações Unidas (ONU) sobre os princípios básicos para a utilização de programas de Justiça Restaurativa em matéria criminal.

Essa resolução prevê, no Item 7 do Título II de seu Anexo, que os processos restaurativos devem ser utilizados somente quando houver o consentimento livre e voluntário da vítima e do ofensor. Ademais, o mesmo item enuncia que a vítima e o ofensor podem revogar esse consentimento a qualquer momento, durante o processo restaurativo ${ }^{17}$.

Apesar de ser um marco importante para a implementação dos pilares da Justiça Restaurativa, a Resolução n. ${ }^{\circ}$ 12, de 2002, da ONU trata o consentimento de forma aberta sem dar balizas e parâmetros para sua mensuração, deixando aos países o tratamento mais adequado na implementação doméstica de programas destinados à aplicação da Justiça Restaurativa.

Do contrato social: princípios do direito político. São Paulo: Edipro, 2020; DWORKIN, Ronald. O império do direito. Tradução de Jefferson Luiz Camargo. São Paulo: Martins Fontes, 1999 e; LOPES, José Reinaldo de Lima. Direitos sociais: teoria e prática. São Paulo: Método, 2006, que, contudo, reconhecem que existe certo consenso ou envolvimento social segundo o qual a vontade expressa na lei, gradualmente, representa a vontade de todos. Logo, para fins meramente didáticos, no presente trabalho, faz-se uso do termo "geral" para referir-se à vontade expressa em lei, considerando que, gradualmente, ela (a lei) abarca a vontade individual de todos os envolvidos.

${ }^{17}$ Item 7 do Título II do Anexo da Resolução n. ${ }^{\circ}$ 12, de 2002, da ONU: "Processos restaurativos devem ser utilizados somente quando houver prova suficiente de autoria para denunciar o ofensor e com o consentimento livre e voluntário da vítima e do ofensor. A vítima e o ofensor devem poder revogar esse consentimento a qualquer momento, durante o processo. Os acordos só poderão ser pactuados voluntariamente e devem conter somente obrigações razoáveis e proporcionais". 
No âmbito nacional, uma das primeiras resoluções a abordar as práticas restaurativas foi a Resolução n. ${ }^{0}$ 118/2014 do Conselho Nacional do Ministério Público (CNMP) ${ }^{18}$, que dispõe sobre a Política Nacional de Incentivo à Autocomposição no âmbito do Ministério Público, a qual separa, especificamente, uma seção com dois artigos para abordar a utilização das práticas restaurativas no âmbito ministerial.

O artigo 13 da resolução elucida em quais casos é recomendada a aplicação dos procedimentos restaurativos no âmbito ministerial ${ }^{19}$, e o artigo 14 , por seu turno, aborda o modo como o procedimento restaurativo ministerial deve ocorrer, bem como os objetivos a serem perseguidos nesses procedimentos ${ }^{20}$.

Todavia, essa resolução é silente acerca dos princípios da Justiça Restaurativa, inclusive o da voluntariedade, não abordando aspectos como a possibilidade de o promotor notificar os envolvidos para a participação em um procedimento restaurativo e muitos outros aspectos. Dessa forma, aparentemente, em nosso sentir, a resolução não visa esgotar o assunto, apenas abre a possibilidade de aplicação da Justiça Restaurativa no âmbito ministerial.

Foi a Resolução n. ${ }^{\circ}$ 225, de 2016, do Conselho Nacional de Justiça (CNJ) que mencionou, em seu artigo 2. ${ }^{\circ}$, a voluntariedade como princípio orientador da Justiça Restaurativa $^{21} \mathrm{e}$, no parágrafo segundo do mesmo artigo, dispôs que o prévio consentimento, livre e espontâneo, de todos os participantes é condição fundamental para a prática restaurativa, sendo possível a retratação até a homologação do acordo restaurativo ${ }^{22}$.

\footnotetext{
${ }^{18}$ BRASIL. Conselho Nacional do Ministério Público. Resolução n. ${ }^{\circ} 118$, de $1 .^{\circ}$ de dezembro de 2014. Dispõe sobre a Política Nacional de Incentivo à Autocomposição no âmbito do Ministério Público e dá outras providências. Diário Oficial da União, Brasília, DF, edição 18, seção 1, p. 48, 27 jan. 2015.

${ }^{19}$ Artigo 13 da Resolução n. ${ }^{\circ}$ 118/2014 do CNMP: "As práticas restaurativas são recomendadas nas situações para as quais seja viável a busca da reparação dos efeitos da infração por intermédio da harmonização entre o(s) seu(s) autor(es) e a(s) vítima(s), com o objetivo de restaurar o convívio social e a efetiva pacificação dos relacionamentos".

${ }^{20}$ Artigo 14 da Resolução n. ${ }^{\circ}$ 118/2014 do CNMP: "Nas práticas restaurativas desenvolvidas pelo Ministério Público, o infrator, a vítima e quaisquer outras pessoas ou setores, públicos ou privados, da comunidade afetada, com a ajuda de um facilitador, participam conjuntamente de encontros, visando à formulação de um plano restaurativo para a reparação ou minoração do dano, a reintegração do infrator e a harmonização social".

${ }^{21}$ Artigo 2. ${ }^{\circ}$ da Resolução n. ${ }^{\circ}$ 225/2016 do CNJ: "São princípios que orientam a Justiça Restaurativa: a corresponsabilidade, a reparação dos danos, o atendimento às necessidades de todos os envolvidos, a informalidade, a voluntariedade, a imparcialidade, a participação, o empoderamento, a consensualidade, a confidencialidade, a celeridade e a urbanidade".

22 Artigo 2. ${ }^{\circ}, \S 2 .^{\circ}$, da Resolução n. ${ }^{\circ}$ 225/2016 do CNJ: "É condição fundamental para que ocorra a prática restaurativa, o prévio consentimento, livre e espontâneo, de todos os seus participantes, assegurada a retratação a qualquer tempo, até a homologação do procedimento restaurativo".
} 
Para que as partes possam decidir com segurança se querem participar ou não, ao serlhes sugerida a aplicação da Justiça Restaurativa, deve ser esclarecido o que é a Justiça Restaurativa, quais são seus objetivos, suas metodologias de atuação e suas consequências. Dessa maneira, cientes também das consequências do processo judicial, as partes (sujeitos) podem decidir com segurança se querem ou não participar da prática restaurativa ${ }^{23}$, conforme o artigo 2. ${ }^{\circ}, \S 3 .^{\circ}$, da Resolução n. ${ }^{\circ}$ 225/2016 do $\mathrm{CNJ}^{24}$.

Ao abordar o atendimento restaurativo em âmbito judicial, elucida que é vedada qualquer forma de coação, bem como a emissão de intimação judicial para que os envolvidos participem das sessões ${ }^{25}$.

Todavia, a Resolução n. ${ }^{\circ}$ 225/2016 do CNJ importou os princípios da Justiça Restaurativa, sem atentar para as peculiaridades do Poder Judiciário. Dessa forma, para que haja a efetiva implementação dos procedimentos restaurativos no âmbito do Judiciário, é necessária a mitigação da voluntariedade individual, em nome da geral, visto que o contexto de substituição judicial desconsidera a vontade originária dos envolvidos e atua de acordo com a persuasão racional em regime derivado da vontade dos envolvidos, por ser o terceiro que delibera sobre os traumas da vida dos que acessam o Poder Judiciário.

\section{A MITIGAÇÃO DO PRINCÍPIO DA VOLUNTARIEDADE EM CONTEXTOS DE SUBSTITUIÇÃO}

A importância dada às relações conflituosas ${ }^{26}$ direcionam o centro das atenções da função ordenadora do direito para as formas judiciais de solução de conflito, levando-nos à

${ }^{23}$ BIANCHINI, Edgar Hrycylo. Justiça Restaurativa: um desafio à práxis jurídica. Campinas: Servanda, 2012, p. $118-126$.

${ }^{24}$ Artigo $2 .^{\circ}$, § 3..$^{\circ}$, da Resolução n. ${ }^{\circ} 225 / 2016$ do CNJ: "Os participantes devem ser informados sobre o procedimento e sobre as possíveis consequências de sua participação, bem como do seu direito de solicitar orientação jurídica em qualquer estágio do procedimento".

${ }^{25}$ Artigo 8. $^{\circ}$ da Resolução n. $225 / 2016$ do CNJ: "Os procedimentos restaurativos consistem em sessões coordenadas, realizadas com a participação dos envolvidos de forma voluntária, das famílias, juntamente com a Rede de Garantia de Direito local e com a participação da comunidade para que, a partir da solução obtida, possa ser evitada a recidiva do fato danoso, vedada qualquer forma de coação ou a emissão de intimação judicial para as sessões".

${ }^{26}$ Spengler elucida que estar em conflito é natural e é normal, pois o conflito é fisiológico e não patológico. Consequentemente, o desdobramento jurídico dessas formas distintas de olhar o conflito é o modo como ocorrerá o tratamento. (SPENGLER, Fabiana Marion. Mediação de conflitos: da teoria à prática. Porto Alegre: Livraria do Advogado, 2016, p. 96). 
Revista Eletrônica de Direito Processual - REDP.

Rio de Janeiro. Ano 15. Volume 22. Número 2. Maio a Agosto de 2021

Periódico Quadrimestral da Pós-Graduação Stricto Sensu em Direito Processual da UERJ

Patrono: José Carlos Barbosa Moreira (in mem.). ISSN 1982-7636. pp. 648-669

www.redp.uerj.br

falsa conclusão de que somente o Judiciário aplica o direito ao caso concreto $^{27}$, quando existe

um universo de pessoas que aplicam o direito no cotidiano sem qualquer intervenção de um terceiro judicial ou privado alheio às relações ${ }^{28}$.

Constata-se que a jurisdição estatal que tutela a ação material por meio do direito de ação processual é sempre substitutiva e, às vezes, não se submete à secundariedade da jurisdição ou à subsidiariedade resolutiva ${ }^{29}$. Portanto, na teoria da jurisdição pela substituição dos sujeitos, há uma mudança de perspectiva de um juiz Homo deus ${ }^{30}$ para um juiz Homo sapiens ${ }^{31}$ que tem a obrigação de tutelar quem tem direito ${ }^{32}$.

27 Não se pretende negar ou subestimar a importância da jurisdição estatal para a proteção de direitos, resguardando os sujeitos envolvidos de situações que antes eram submetidas a sucessivas e maciças violações, visto que, em última ratio, será a jurisdição pública ou privada a solução racional, humanizada, justa e equitativa dos conflitos existentes. Portanto, constata-se que o processo é uma garantia contra o exercício arbitrário de suas próprias razões, pois atua por meio da contenção de abusos. O processo não apenas limita os arbítrios dos grandes litigantes e dos violadores de direitos, como também substitui a vontade dos sujeitos envolvidos na solução de seus problemas. A substituição não é um problema, pois a jurisdição estatal é um modo legítimo e necessário de resolução, administração e transformação de CPIS, sendo imprescindível para diversas situações e direitos envolvidos, a exemplo das ações necessárias. O problema é sobrepor a solução judicial estatal dos CPIS às demais formas de tratamento de CPIS, de forma a priorizá-la e enaltecê-la em detrimento da solução originária, negociada, dialogada e cooperada entre os sujeitos envolvidos no pleno exercício da capacidade humana relacional ou autocompositiva.

${ }^{28}$ SILVA, Sandoval Alves da; ALVES, Camille de Azevedo; SIQUEIRA, João Renato Rodrigues. O papel dos sujeitos na Justiça Restaurativa aplicada a casos cíveis judicializados: protagonismo ou substituição? [2020]. No prelo.

${ }^{29}$ Constata-se que a jurisdição estatal é sempre substitutiva, pois os sujeitos serão representados por terceiros que falarão e decidirão por eles, mas nem sempre é subsidiária, pois existem ações necessárias, isto é, demandas que necessariamente devem passar pelo Poder Judiciário, como os casos envolvendo menores, ações penais públicas e outras. Dessa forma, a depender do caso tutelado, a jurisdição estatal é subsidiária, pois só é exercida quando não ocorre a atuação resolutiva voluntária do direito violado ou ameaçado, mas sempre será substitutiva. (SILVA, Sandoval Alves da; ALVES, Camille de Azevedo; SIQUEIRA, João Renato Rodrigues. O papel dos sujeitos na Justiça Restaurativa aplicada a casos cíveis judicializados: protagonismo ou substituição? [2020]. No prelo).

30 Juiz Homo deus é a autoridade legitimada para dizer o que é certo ou errado independentemente da racionalidade dos envolvidos. (SILVA, Sandoval Alves da; ALVES, Camille de Azevedo; SIQUEIRA, João Renato Rodrigues. O papel dos sujeitos na Justiça Restaurativa aplicada a casos cíveis judicializados: protagonismo ou substituição? [2020]. No prelo). Um exemplo de sistema judicial em que se vislumbra a figura do juiz Homo deus é o sistema germânico primitivo, no qual, por exemplo, o papel da prova não era fundar a convicção do juiz, mas apenas demonstrar a manifestação de divindades em favor da parte que tem razão (MARINONI, Luiz Guilherme; ARENHART, Sérgio Cruz; MITIDIERO, Daniel. Novo Curso de Processo Civil: teoria do processo civil. São Paulo: Revista dos Tribunais, 2015. v. 1. p. 535-536).

${ }^{31}$ Juiz Homo sapiens é a autoridade legitimada pela vontade coletiva ou individual para agir racionalmente em regime de substituição da vontade e da decisão dos sujeitos envolvidos (SILVA, Sandoval Alves da; ALVES, Camille de Azevedo; SIQUEIRA, João Renato Rodrigues. O papel dos sujeitos na Justiça Restaurativa aplicada a casos cíveis judicializados: protagonismo ou substituição? [2020]. No prelo.).

32 SILVA, Sandoval Alves da; ALVES, Camille de Azevedo; SIQUEIRA, João Renato Rodrigues. O papel dos sujeitos na Justiça Restaurativa aplicada a casos cíveis judicializados: protagonismo ou substituição? [2020]. No prelo. 
No exercício do direito de ação processual, há uma dupla substituição e "incapacitação"33 relacional do sujeito, uma postulatória e outra decisória. A primeira decorre da obrigatoriedade de constituir advogado público ou privado para ingressar com algumas demandas judiciais, que comportam exceção no jus postulandi, embora o advogado, o Ministério Público e o defensor público sejam essenciais à justiça jurisdicional. Assim, os fatos vão ao conhecimento do juiz não por quem os vivenciou, mas por um terceiro que poderá até distorcê-los para melhor fundamentar sua pretensão jurídica processual ${ }^{34}$.

Em seguida, os sujeitos serão novamente substituídos, uma vez que os CPIS serão solucionados pelo juiz, o que "incapacita" relacionalmente os sujeitos para a resolução dos CPIS de forma dialogada e cooperada.

Não se podem negar os esforços processuais para tornar o processo mais dialogado e mais cooperado, mas, apesar de todas as tentativas de mitigar a substituição, ela é intrínseca e constitutiva da jurisdição, de forma que, mesmo que o processo tenha um diálogo intenso, a decisão será sempre do juiz ou do árbitro em regime de substituição, razão pela qual alguns afirmam que não haveria diálogo no âmbito processual, haveria antes responsabilidade judicial ${ }^{35}$.

O juiz sai de sua inércia natural a pedido dos sujeitos, substituindo-os no plano derivado. Tal solicitação de substituição acarreta para o juiz o dever de atuar no lugar os sujeitos (na resolução, na administração e na transformação de CPIS) de forma racional, justa e harmônica, em um regime derivado de vontades, para que haja o máximo de aproximação possível entre o agir processual derivado e o agir material originário que foi objeto de vedação e de limitação da autotutela ${ }^{36}$.

Ademais, a teoria da substituição esclarece que, historicamente, a autotutela e a autocomposição são anteriores à jurisdição. A ação processual surge como substituta da ação

\footnotetext{
${ }^{33}$ No ato da demanda, os sujeitos envolvidos no CPIS "incapacitam-se" voluntariamente para resolver, administrar ou transformar seus CPIS perante o juiz, rogando que ele os substitua. Logo, utiliza-se o termo "incapacidade" entre aspas para fazer referência à inanição da pessoa ante o exercício de seu protagonismo na resolução, na administração e na transformação de CPIS (SILVA, Sandoval Alves da; ALVES, Camille de Azevedo; SIQUEIRA, João Renato Rodrigues. O papel dos sujeitos na Justiça Restaurativa aplicada a casos cíveis judicializados: protagonismo ou substituição? [2020]. No prelo.).

${ }^{34}$ SILVA, Sandoval Alves da. O dever fundamental da persecução da verdade possível ou provável no CPC de 2015. Revista dos Tribunais, São Paulo, v. 106, n. 980, p. 297-327, jun. 2017, p. 298.

${ }^{35}$ SILVA, Sandoval Alves da; GÓES, Gisele Santos Fernandes; JESUS, Thiago Vasconcellos. A necessidade da premissa dialógica como interesse processual nos conflitos coletivos. [2020]. No prelo.

${ }^{36}$ SILVA, Sandoval Alves da. O dever fundamental da persecução da verdade possível ou provável no CPC de 2015. Revista dos Tribunais, São Paulo, v. 106, n. 980, p. 297-327, jun. 2017, p. 311-312.
} 
material (autotutela e autocomposição) e permanece a ela vinculada, sob pena de ser não uma substituição, mas uma usurpação de vontade segundo os padrões da ordem jurídica ${ }^{37}$.

Diante do exposto, observa-se que, no paradigma atual, embora haja uma constante mudança, busca-se o retorno à primariedade quando demandado o Judiciário, isto é, o retorno à ação material, o retorno à solução, administração e transformação negociada, dialogada e cooperada dos CPIS pelos próprios sujeitos envolvidos. Nesse contexto, a Justiça Restaurativa apresenta-se como uma forma de justiça que devolve o protagonismo aos envolvidos ${ }^{38}$, para que exerçam consciente, livre e voluntariamente as deliberações sobre os traumas vividos.

Todavia, conforme apresentado na seção anterior, o princípio da voluntariedade concebido na Justiça Restaurativa como voluntariedade individual de cada participante ao consentir engajar-se no procedimento restaurativo - pode, em determinadas situações, colidir com a voluntariedade geral. Assim, a lei, enquanto reflexo da vontade geral, determina que o Judiciário substitua os envolvidos na resolução de seus CPIS, decidindo por eles com base no ordenamento jurídico, isto é, em uma substituição relacional decisória.

Em outras palavras, no ato da demanda, o indivíduo "incapacita-se", e o advogado, por substituição, no exercício da capacidade postulatória, pede para que o juiz substitua o demandante, que abre mão da sua voluntariedade individual originária para que o juiz decida em um regime de "incapacitação" relacional decisória.

Porém, o Poder Judiciário pode - e, pelo CPC de $2015^{39}$, deve - receber aquele pleito e, processualmente, tentar devolvê-lo para que os envolvidos, primeiramente, tentem resolver pelo exercício de suas razões relacionais aqueles CPIS $^{40}$, antes que o juiz os substitua relacional e decisoriamente.

${ }^{37}$ SILVA, Sandoval Alves da; ALVES, Camille de Azevedo; SIQUEIRA, João Renato Rodrigues. O papel dos sujeitos na Justiça Restaurativa aplicada a casos cíveis judicializados: protagonismo ou substituição? [2020]. No prelo.

38 SILVA, Sandoval Alves da; ALVES, Camille de Azevedo; SIQUEIRA, João Renato Rodrigues. O papel dos sujeitos na Justiça Restaurativa aplicada a casos cíveis judicializados: protagonismo ou substituição? [2020]. No prelo.

${ }^{39} \mathrm{No}$ CPC de 2015 , verifica-se esse estímulo ao protagonismo dos envolvidos na postulação da obrigatoriedade das audiências de conciliação e de mediação antes da apreciação do mérito pelo juiz. O artigo 334, caput, elucida: "Se a petição inicial preencher os requisitos essenciais e não for o caso de improcedência liminar do pedido, o juiz designará audiência de conciliação ou de mediação com antecedência mínima de 30 (trinta) dias, devendo ser citado o réu com pelo menos 20 (vinte) dias de antecedência".

${ }^{40}$ Alguns autores, como Cazelli e Ferro, criticam o CPC de 2015, que instituiu como fase judicial obrigatória as tratativas de acordo em audiências de conciliação ou de mediação. No entanto, o regramento obriga a realização dessas audiências apenas durante a fase judicial, não havendo obrigação de sua realização em 
Revista Eletrônica de Direito Processual - REDP.

Rio de Janeiro. Ano 15. Volume 22. Número 2. Maio a Agosto de 2021

Periódico Quadrimestral da Pós-Graduação Stricto Sensu em Direito Processual da UERJ

Patrono: José Carlos Barbosa Moreira (in mem.). ISSN 1982-7636. pp. 648-669

www.redp.uerj.br

Portanto, no Judiciário os envolvidos são substituídos, isto é, abrem mão de sua vontade individual originária, de forma que o juiz pode intimá-los a praticar e a participar de determinados atos judiciais e pode mesmo decidir por eles o caso, assumindo obrigações pelos sujeitos envolvidos nos CPIS, salvo se ficar claro que tais sujeitos voluntariamente rejeitam a resolução autocompositiva e optam pela solução judicial em regime de substituição ${ }^{41}$.

Assim, se o juiz pode, contra a vontade individual do substituído, impor-lhe o ônus de participar de um procedimento autoritário de decisão unilateral, em que a vontade originária dos sujeitos envolvidos é substituída por um terceiro, por que não poderia intimar a participar de um procedimento democrático de participação ativa e decisão compartilhada em que os sujeitos podem dizer clara e voluntariamente como querem resolver o conflito?

Logo, o juiz pode intimar os envolvidos a participarem de um processo autocompositivo que estimule o seu protagonismo na solução, na administração e na transformação de seus CPIS, o que, embora contrarie a vontade individual de participar, está em consonância com (1) a vontade individual de ser substituído, expressa no ato da demanda, e com (2) a vontade geral expressa no ordenamento jurídico de (2.1) substituir os sujeitos

momento anterior ao ajuizamento da demanda. Dessa forma, o CPC de 2015 foi acanhado nesse tópico, pois, para a concretização do justo acionamento da Justiça, era necessária uma previsão mais contundente no que tange à necessidade de o legitimado demonstrar razão relevante para a movimentação do Judiciário, incluída a comprovação da impossibilidade de solução do litígio previamente de forma extrajudicial (CAZELLI, Vinícius Ribeiro; FERRO, Ricardo Rage. Conciliação e mediação obrigatórias para um uso racional da máquina judiciária: experiência na União Europeia e na Colômbia. Revista Eletrônica de Direito Processual, Rio de Janeiro, ano 14, v. 21, n. 2, maio/ago. 2020, p. 405).Outra corrente, representada por autores como Luiz Guilherme Marinoni, Sérgio Cruz Arenhart e Daniel Mitiero, compreende que a instituição de audiências de conciliação e de mediação obrigatórias foi um avanço introduzido pelo CPC para estimular a autocomposição (MARINONI, Luiz Guilherme; ARENHART, Sérgio Cruz; MITIDIERO, Daniel. Novo Código de Processo Civil comentado. 3. ed., rev. atual. e ampl. São Paulo: Revista dos Tribunais, 2017, p. 440). A terceira corrente manifesta-se desfavoravelmente à imposição e à obrigatoriedade da solução consensual de conflitos. Para Francisco José Cahali, a problemática está na relativização do princípio da autonomia da vontade, pois, se uma das características da mediação é sua voluntariedade, poderia ser ela uma condição da ação? Observe-se que o CPC traz uma contradição. A positivação do princípio da autonomia da vontade impediria a mediação obrigatória, na medida em que a voluntariedade aparece como princípio implícito. Todavia, o legislador estabeleceu que o não comparecimento injustificado das partes à audiência de conciliação é considerado ato atentatório à dignidade da justiça e será sancionado com multa. Para Cahali, não parece ser essa a forma correta de promover tão nobre instituto (CAHALI, Francisco José. Curso de arbitragem: mediação, conciliação, tribunal multiportas. São Paulo: Revista dos Tribunais, 2020). Por fim, há uma quarta corrente, pouco explorada academicamente, segundo a qual a designação de audiência de conciliação e de mediação viola o princípio constitucional do acesso à justiça, artigo 5. ${ }^{\circ}, \mathrm{XXXV}$, da Constituição da República Federativa do Brasil (CRFB) de 1988, por inviabilizar, ainda que momentaneamente, a efetiva entrega da prestação jurisdicional.

${ }^{41}$ Artigo 334, § 4. ${ }^{\circ}$, do CPC/2015: "A audiência não será realizada: I - se ambas as partes manifestarem, expressamente, desinteresse na composição consensual; II - quando não se admitir a autocomposição”. 
envolvidos nas demandas, intimando-os, e de (2.2) incentivar a autocomposição, quando se trata do procedimento de tentativa de autocomposição, salvo se ambas as partes manifestarem, expressamente, desinteresse na composição consensual ou não se admitir a autocomposição, nos termos dos incisos do $\S 4 .^{\circ}$ do artigo 334 do CPC.

Assim, ao intimar para a prática restaurativa, o juiz está escolhendo pelos envolvidos (isto é, substituindo-os) um procedimento que vai permitir que os próprios sujeitos escolham coletivamente o meio de resolutividade que melhor lhes atende no exercício de sua voluntariedade relacional, sem optar pelo regime de substituição decisória sobre os traumas de suas vidas. Portanto, os envolvidos assumem o protagonismo na solução, na administração e na transformação de seus CPIS.

\section{CONCLUSÃO}

A Justiça Restaurativa, de acordo com fontes histórico-antropológicas, remonta a tradições presentes em diversas comunidades espalhadas em vários continentes. Nessas comunidades, inexistia a figura centralizadora de um juiz, detentor do poder coercitivo e responsável pela solução, pela administração ou pela transformação dos CPIS.

Quando um CPIS lesionava ou ameaçava o convívio harmônico da comunidade, buscava-se, comunitariamente, restabelecer o equilíbrio afetado. Assim, a transgressão desencadeava diversas reações orientadas para o restabelecimento do equilíbrio rompido. A comunidade compreendia-se corresponsável pelo ato ilícito sem, no entanto, excluir a responsabilidade e a penalização do transgressor.

Portanto, a origem da Justiça Restaurativa está ligada a uma forma colaborativa de resolução, de administração e de transformação de CPIS com a participação de toda a comunidade, isto é, de todos os afetados pelo conflito. Dessa forma, a Justiça Restaurativa objetiva garantir o protagonismo dos envolvidos em CPIS, buscando métodos participativos de deliberação para solucioná-los, administrá-los ou transformá-los.

Um dos pilares da Justiça Restaurativa é a voluntariedade. Desse modo, para que um procedimento seja considerado restaurativo, é necessária a participação voluntária dos envolvidos. Portanto, ninguém deve ser coagido a participar, tampouco a continuar no processo e/ou a se comunicar contra a sua vontade. 
Compreendendo esse pré-requisito para a aplicabilidade da Justiça Restaurativa, os principais marcos legislativos internacionais e nacionais destacam a importância da voluntariedade e do consentimento para a participação nos procedimentos restaurativos, porém tal voluntariedade deve ser analisada de forma sistêmica e completa em relação aos demais processos de tratamento de CPIS, em especial, ao processo judicial.

A Resolução n. ${ }^{\circ}$ 12, de 2002, da ONU sobre os princípios básicos para a utilização de programas de Justiça Restaurativa em matéria criminal prevê que os procedimentos restaurativos devem ser utilizados somente quando houver o consentimento livre e voluntário da vítima e do ofensor e que ambos podem revogá-lo a qualquer momento, ao longo do processo restaurativo.

A Resolução da ONU, apesar de ser um marco importante para a implementação dos pilares da Justiça Restaurativa, trata o consentimento de forma aberta, sem dar balizas e parâmetros para sua mensuração, deixando aos países o tratamento mais adequado na implementação doméstica de programas de Justiça Restaurativa.

No âmbito nacional, a Resolução n. ${ }^{\circ}$ 118/2014 do CNMP sobre a Política Nacional de Incentivo à Autocomposição no âmbito do Ministério Público aborda a utilização das práticas restaurativas no âmbito ministerial, elucidando (1) os casos em que é recomendada a aplicação dos procedimentos restaurativos (artigo 13) e (2) o modo como o procedimento deve ocorrer, bem como os objetivos a serem perseguidos (artigo 14).

Porém, essa resolução é silente acerca dos princípios da Justiça Restaurativa, inclusive o da voluntariedade, não abordando, por exemplo, aspectos como a possibilidade de o promotor notificar os envolvidos para a participação em um procedimento restaurativo. Desse modo, aparentemente, a Resolução não visa esgotar o assunto, apenas abre a possibilidade de aplicação da Justiça Restaurativa no âmbito ministerial.

Foi a Resolução n. ${ }^{\circ} 225$, de 2016, do CNJ que mencionou, em seu artigo 2. ${ }^{\circ}$, a voluntariedade como princípio orientador da Justiça Restaurativa e, no parágrafo segundo do mesmo artigo, dispôs que o prévio consentimento, livre e espontâneo, de todos os participantes é condição fundamental para a prática restaurativa, sendo possível a retratação até a homologação do acordo restaurativo.

A Resolução do CNJ, ao abordar o atendimento restaurativo em âmbito judicial, torna claro que é vedada qualquer forma de coação, bem como a emissão de intimação judicial 
para que os envolvidos participem das sessões. Todavia, constata-se que a Resolução importou os princípios da Justiça Restaurativa e não atentou para as peculiaridades do Poder Judiciário.

Uma das características do Poder Judiciário que precisa ser mais bem avaliada quando se tratar da possibilidade ou não de intimar os envolvidos a participarem de procedimentos restaurativos é a substitutividade deliberativa que o juiz exerce em nome dos sujeitos envolvidos.

A jurisdição estatal que tutela a ação material por meio do direito de ação processual é sempre substitutiva. Portanto, no exercício do direito de ação processual, há uma dupla substituição e "incapacitação" relacional do sujeito.

A substituição relacional postulatória decorre da obrigatoriedade de constituir advogado público ou privado para ingressar com algumas demandas judiciais. Em seguida, os sujeitos serão novamente substituídos. Trata-se, dessa vez, de uma substituição relacional decisória, pois os CPIS serão solucionados decisoriamente pelo juiz.

Tal solicitação de substituição acarreta ao juiz o dever de fazer os envolvidos participarem da resolução, da administração e da transformação de CPIS de forma racional, justa e harmônica, em um regime derivado de vontades, para que haja o máximo de aproximação possível entre o agir processual derivado e o agir material originário.

Ademais, no contexto atual, busca-se o retorno à primariedade, quando demandado o Judiciário, isto é, o retorno à ação material relacional ou autocompositiva, o retorno à solução, administração e transformação negociada, dialogada e cooperada dos CPIS pelos próprios sujeitos envolvidos. É nesse paradigma que se apresenta a Justiça Restaurativa: como um mecanismo de justiça que devolve o protagonismo aos envolvidos.

Todavia, o princípio da voluntariedade, concebido na Justiça Restaurativa como voluntariedade individual de cada participante ao consentir engajar-se no procedimento restaurativo, pode, em determinadas situações, colidir com a voluntariedade geral, estabelecida em lei. Em outras palavras, a lei, enquanto reflexo da vontade geral, determina que o Judiciário substitua os envolvidos na resolução de seus CPIS, decidindo por eles com base no ordenamento jurídico em uma substituição relacional decisória.

Dessa forma, no ato da demanda, o indivíduo "incapacita-se", e o advogado, por substituição, no exercício da capacidade postulatória, pede para que o juiz substitua o 
demandante, que renuncia a sua voluntariedade individual originária para que o juiz decida em um regime de "incapacitação" relacional decisória.

Porém, o Judiciário pode - e, pelo CPC de 2015, deve - receber aquele pleito e, processualmente, tentar devolvê-lo para que os envolvidos, primeiramente, tentem resolver aqueles CPIS pelo exercício de suas razões relacionais, sem a intervenção judicial e sem que haja imediatamente uma substituição relacional e decisória.

Logo, em atenção ao direito do procedimento mais adequado à tutela, o juiz pode intimar os envolvidos a participarem de um processo autocompositivo que estimule o seu protagonismo na solução, na administração e na transformação de seus CPIS. Isso, embora contrarie a vontade individual de participar, está em consonância com (1) a vontade individual de ser substituído, expressa no ato da demanda, e com (2) a vontade geral expressa no ordenamento jurídico de (2.1) substituir os sujeitos envolvidos nas demandas, intimandoos, e de (2.2) incentivar a autocomposição, salvo se ambas as partes manifestarem, expressamente, desinteresse na composição consensual ou não se admitir a autocomposição, nos termos dos incisos do $\S 4 .^{\circ}$ do artigo 334 do CPC.

Assim, se o processo mais indicado àquela tutela for a Justiça Restaurativa, o juiz poderá intimar os envolvidos para a prática restaurativa, visto que o juiz estará escolhendo pelos envolvidos substituídos um procedimento que vai permitir que eles decidam coletivamente (isto é, não sejam substituídos decisoriamente). Por conseguinte, eles assumem o protagonismo na solução, na administração e na transformação de seus CPIS, em um estímulo à primariedade, ressalvadas as manifestações contrárias à autocomposição.

\section{REFERÊNCIAS}

BIANCHINI, Edgar Hrycylo. Justiça Restaurativa: um desafio à práxis jurídica. Campinas: Servanda, 2012.

BRASIL. Conselho Nacional de Justiça. Resolução n. ${ }^{\circ}$ 225, de 31 de maio de 2016. Dispõe sobre a Política Nacional de Justiça Restaurativa no âmbito do Poder Judiciário e dá outras providências. DJe/CNJ, n. 91, p. 28-33, 2 jun. 2016. Disponível em: https://atos.cnj.jus.br/atos/detalhar/2289. Acesso em: 27 jul. 2020.

BRASIL. Conselho Nacional do Ministério Público. Resolução n. ${ }^{\circ} 118$, de 1. ${ }^{\circ}$ de dezembro de 2014. Dispõe sobre a Política Nacional de Incentivo à Autocomposição no âmbito 
do Ministério Público e dá outras providências. Diário Oficial da União, Brasília, DF, edição 18, seção 1, p. 48, 27 jan. 2015.

BRASIL. Lei n. ${ }^{\circ}$ 13.105, de 16 de março de 2015. Código de Processo Civil. Diário Oficial da União, Brasília, DF, 17 mar. 2015. Disponível em: http://www.planalto.gov.br/ccivil_03/_ato2015-2018/2015/lei/113105.htm. Acesso em: 23 ago. 2020.

CAHALI, Francisco José. Curso de arbitragem: mediação, conciliação, tribunal multiportas. São Paulo: Revista dos Tribunais, 2020.

CAZELLI, Vinícius Ribeiro; FERRO, Ricardo Rage. Conciliação e mediação obrigatórias para um uso racional da máquina judiciária: experiência na União Europeia e na Colômbia. Revista Eletrônica de Direito Processual, Rio de Janeiro, ano 14, v. 21, n. 2, p. 397-421, maio/ago. 2020.

DWORKIN, Ronald. O império do direito. Tradução de Jefferson Luiz Camargo. São Paulo: Martins Fontes, 1999.

JACCOUD, Mylène. Princípios, tendências e procedimentos que cercam a justiça restaurativa. In: SLAKMON, Catherine; DE VITTO, Renato Campos Pinto; PINTO, Renato Sócrates Gomes (org.). Justiça restaurativa. Brasília, DF: Ministério da Justiça; Programa das Nações Unidas para o Desenvolvimento, 2005. p. 163-188. Disponível em: https://carceraria.org.br/wp-content/uploads/2014/07/Coletanea-deArtigos-Livro-Justi\%C3\%A7a-Restaurativa.pdf. Acesso em: 31 jul. 2020.

LOPES, José Reinaldo de Lima. Direitos sociais: teoria e prática. São Paulo: Método, 2006. MARINONI, Luiz Guilherme; ARENHART, Sérgio Cruz; MITIDIERO, Daniel. Novo Curso de Processo Civil: teoria do processo civil. São Paulo: Revista dos Tribunais, 2015. v. 1. p. 485-556.

MARINONI, Luiz Guilherme; ARENHART, Sérgio Cruz; MITIDIERO, Daniel. Novo Código de Processo Civil comentado. 3. ed., rev. atual. e ampl. São Paulo: Revista dos Tribunais, 2017.

MARSHALL, Chris; BOYACK, Jim; BOWEN, Helen. Como a Justiça Restaurativa assegura a boa prática: uma abordagem baseada em valores. In: SLAKMON, Catherine; DE VITTO, Renato Campos Pinto; PINTO, Renato Sócrates Gomes (org.). Justiça Restaurativa: coletânea de artigos. Brasília, DF: Ministério da Justiça; 
Programa das Nações Unidas para o Desenvolvimento, 2005. p. 267-277. Disponível em: https://carceraria.org.br/wp-content/uploads/2014/07/Coletanea-de-ArtigosLivro-Justi\%C3\%A7a-Restaurativa.pdf. Acesso em: 31 jul. 2020.

MARSHALL, Tony F. Restorative Justice: An Overview. London: Home Office Research and Development Statistics Directorate, 1999.

MENDES, Conrado Hübner. Direitos fundamentais, separação de poderes e deliberação. São Paulo: Saraiva, 2011.

OLIVEIRA, Frederico dos Santos. Círculo restaurativo e procedimento judicial: análise de uma axiologia (as)simétrica. Caruaru: Asces, 2019.

ORGANIZAÇÃO DAS NAÇÕES UNIDAS. Conselho Econômico e Social. Estabelece princípios básicos para utilização de programas de Justiça Restaurativa em matéria criminal. Resolução $n^{\circ}$ 12, de 24 de julho de 2002. Disponível em: http://juridica.mppr.mp.br/arquivos/File/MPRestaurativoEACulturadePaz/Material_d e_Apoio/Resolucao_ONU_2002.pdf. Acesso em: 28 jul. 2020.

PINTO, Renato Sócrates Gomes. Justiça restaurativa é possível no Brasil? In: SLAKMON, Catherine; DE VITTO, Renato Campos Pinto de; PINTO, Renato Sócrates Gomes (org.). Justiça restaurativa: coletânea de artigos. Brasília, DF: Ministério da Justiça; Programa das Nações Unidas para o Desenvolvimento, 2005. p. 19-39. Disponível em: https://carceraria.org.br/wp-content/uploads/2014/07/Coletanea-de-Artigos-LivroJusti\%C3\%A7a-Restaurativa.pdf. Acesso em: 31 jul. 2020.

ROUSSEAU, Jean-Jacques. Do contrato social: princípios do direito político. São Paulo: Edipro, 2020.

SILVA, Elizabet Leal da. Justiça restaurativa como meio alternativo de solução de conflito. Arquivo Jurídico, Teresina, v. 1, n. 6, p. 22-38, jan./jun. 2014.

SILVA, Karina Duarte Rocha da. Justiça Restaurativa e sua aplicação no Brasil. 2007. 83 f. Monografia (Bacharelado em Direito) - Faculdade de Direito, Universidade de Brasília, Brasília, DF, 2007.

SILVA, Sandoval Alves da. O dever fundamental da persecução da verdade possível ou provável no CPC de 2015. Revista dos Tribunais, São Paulo, v. 106, n. 980, p. 297327, jun. 2017. 
SILVA, Sandoval Alves da; ALVES, Camille de Azevedo; SIQUEIRA, João Renato Rodrigues. O papel dos sujeitos na Justiça Restaurativa aplicada a casos cíveis judicializados: protagonismo ou substituição? [2020]. No prelo.

SILVA, Sandoval Alves da; GÓES, Gisele Santos Fernandes; JESUS, Thiago Vasconcellos. A necessidade da premissa dialógica como interesse processual nos conflitos coletivos. [2020]. No prelo.

SILVA, Sandoval Alves da; SIQUEIRA, João Renato Rodrigues. Acesso à justiça no Projeto "Escrevendo e Reescrevendo a Nossa História" (Pernoh). Revista InterAção, [s.l.], v. 10, n. 2, p. 41-51, jun./dez. 2019.

SPENGLER, Fabiana Marion. Mediação de conflitos: da teoria à prática. Porto Alegre: Livraria do Advogado, 2016.

TORRES CARRILLO, Alfonso. El retorno a la comunidad: problemas, debates y desafíos de vivir juntos. Bogotá: El Búho, 2013.

ZEHR, Howard. Justiça restaurativa: teoria e prática. Tradução de Tônia Van Acker. 2. ed. ampl. e atual. São Paulo: Palas Athena, 2015. 